\title{
Interpretation According to Context
}

\author{
Raad Abdullah Fayyadh \\ Al-Salam University College, Baghdad, Iraq \\ raaddhma@gmail.com
}

\section{KEYWORDS: $\quad$ Interpretation, Imperative, Context, Judgment, Vocabulary.}

\begin{abstract}
:
Standing and thinking about the context of the verse or verses and linking to reach a knowledge of what is meant by them, between them and them, studying and that studying the Qur'an in its truth is one of the meanings of contemplating the verses of the Noble Qur'an through the context of the verse and the context of the passage, and that it is separate from it, whether in the same Surah or other, and falls under it. There are also two types of Qur'anic types: the context of the surah and the context of the Qur'an. The impact of this research is evident to us as this study can be applied to all interpretations, even if the study is generalized to the rest of the vocabulary, Interpretation of the Qur'an will facilitate, as the topic plan marked: (Interpretation according to the context) was to be divided into three sections. In the first section I spoke about the meaning of the Qur'anic context and context, and in the second topic I explained the meaning of contextual judgment and the overall meanings, and in the third topic I showed the importance of interpretation by context. Through the different meanings of the word "q $\mathrm{d}$ a", then the conclusion was included in it the most important results of the research.
\end{abstract}




\title{
التفسير بمقتضى السياق
}

\author{
م.د. رعد عبد الله فياض
}

كلية السلام الجامعة، بغداد، العراق

raaddhma@gmail.com

$$
\text { الكلمات المفتاحية التفسير، المقتضى، السياق، الحكم، المفردة. }
$$

Crossref doi) https://doi.org/10.51345/.v32i2.388.g216

\section{ملخص البحث:}

الوقوف على معالي القر آن من خلال التدبر والتفكر، ولا شيء أنفع للعبد في معاشه ومعاده من تدبر القر آن، وحقيقة التدبر هي إمعان النظر والتفكر في سياق الآية أو الآيات والربط بينها للوصول إلى معرفة المراد منها، وبالتالي ينتج العمل بها، وآن دراسة السياق القر آين في حقيقته هو أحد معاني تدبر آيات القر آن الكريم من خحلال سياق الآية وسياق المقطع، وأنْ يكون منفصلا عنه سواء في نفس السورة أو غيرها، ويدخل تحته نوعين أيضا من أنواع السياق القرآي: سياق السورة وسياق القرآن، وتنجلى هولى لنا

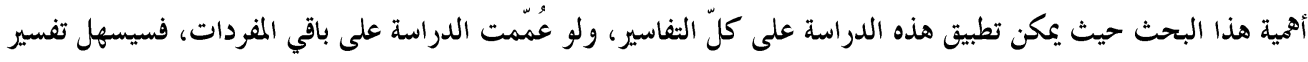

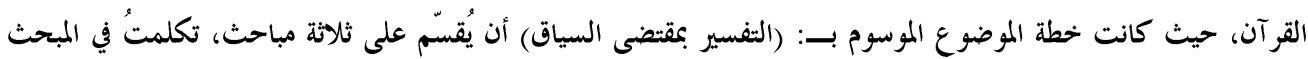
الأول عن معنى السياق والسياق القرآين، وفي المبحث الثاني، بينت معنى حكمية السياق والمعالي الكلية، وفي المبحث الثالث بيّت ' أهمية التفسير بالسياق من خلال اختلاف معاني مفردة (ق ض ى)، ثم الخاتمة وقد أدرجت فيها أهم نتائج البحث.

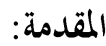

إنّ دراسة السياق القرآني في حقيقته هو المعنى الآخر لمعنى تدبر للقرآن، ولقد سلك العلماء طرقا في تفسىر كلام الله عز وجل أحسنها: تفسير القرآن بالقرآن نفسه، ولتفسير القرآن بالقرآن مرتبتان أعلاهما: أن يكون في محل واحد؛ كأن يكون عقبه، وهذه المرتبة يدخل تحتها نوعين من أنواع السياق: أو لا: سياق الآية وسياق المقطع. ثانيا: أنْ يكون منفصلا عنه سواء في نفس السورة أو غيرها، و يدخل تحته نوعان أيضا من أنواع السياق القر آني: سياق السورة وسياق القر آن.

و منه يمكن أن نقول بأن السياق القر آني أصل من أصول التفسير المعتبرة، بل من أهمها. لذا كان سبب اختيار الموضوع (التفسير .كقتضى السياق) لأن للسياق أثرا بارزا في ترجيح المحتملات، و بيان المجملات، ووي تنقيح التفسير من الدخيل والاسرائيليات، ودفع ما يتوهم أنه تعارض بين الآيات. 
و اقتضى الموضوع أن يُقسّم على ثلاثة مباحث، تكلمتُ في المبحث الأول عن معنى السياق والسياق

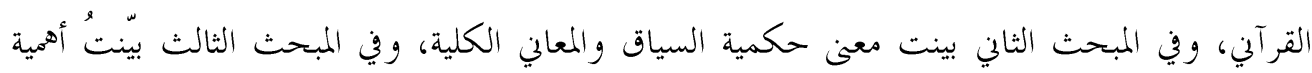
التفسير بالسياق من خلال اختلاف معاني مفردة (ق ض ى).

\section{المبحث الأول: السياق القر آين}

\section{المطلب الأول تعريف السياق لغة واصطلاحاً}

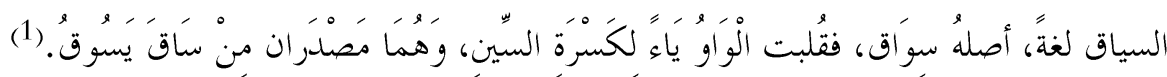

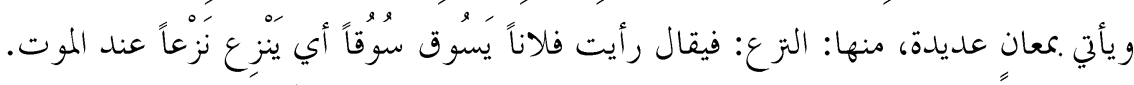

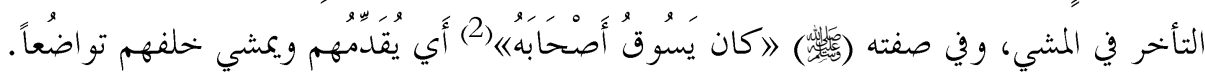

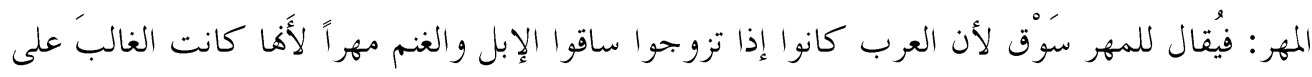
(3) أمو الهم. (1)

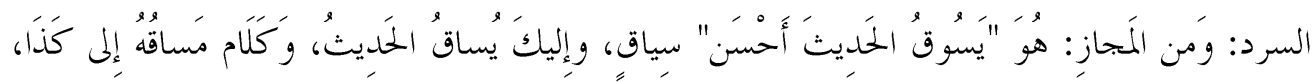

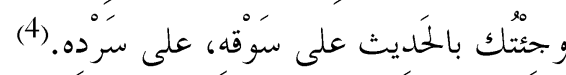

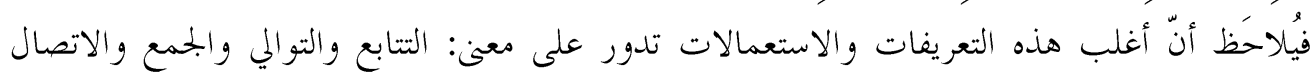
و التسلسل. و اصطلاحاً: مثلما اختلف اللغويون في معنى السياق اختلف اهل الاصطلاح، ومن ذلك: سياق الكلام: تتابعه، وأسلوبه الذي يجري عليه.(5) دلالة السياق هي: "فهم النص بمر اعاة ما قبله وما بعده".

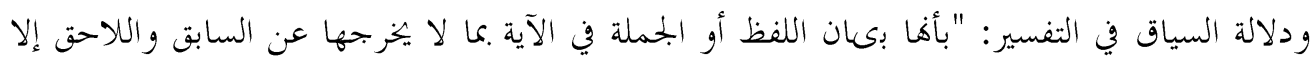
بدليل صحيح يجب التسليم له"(6). أو هو: "تتابع المعاني و انتظامها في سلك الألفاظ القرآنية، لتبلغ غايتها الموضوعية في بيان المعنى المقصود، دون انقطاع أو انفصال"(7). وعرف بعضهم السياق القرآني بأنه: "ما يحيط بالنص من عوامل داخلية أو خارجية لها أثر في فهمه: من

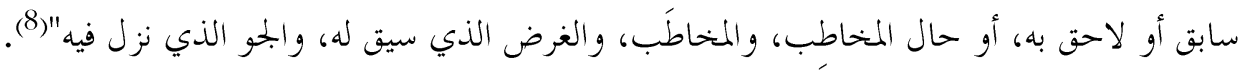

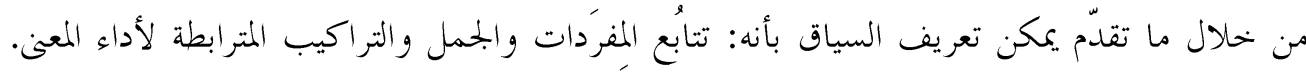
وعليه يكون السياق القرآي: تتابع المفردات والجمل والتراكيب القر آنية المترابطة لأداء المعنى. (9) 


\section{المطلب الثاني: أهمية السياق القر آني في التفسير}

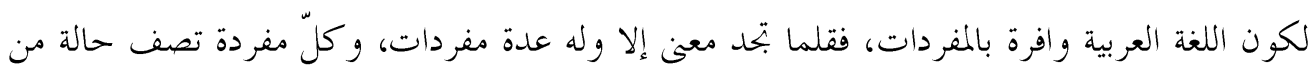

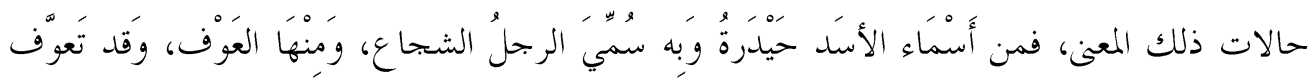

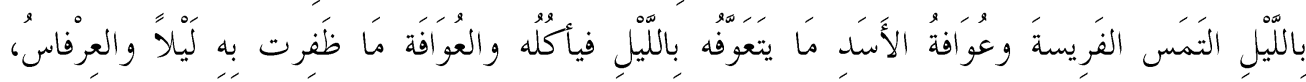

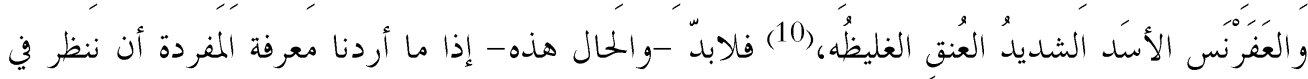
سياق الجملة التي أدرجت فيها.

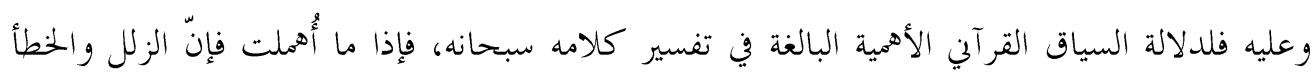
و واقع لا عحالة، وما أعظم الخطأ في تفسير القرآل آن.

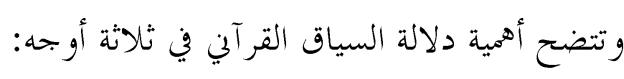
الوجه الأول: دلالة السياق عند تفسير القرآن بالقر آن.

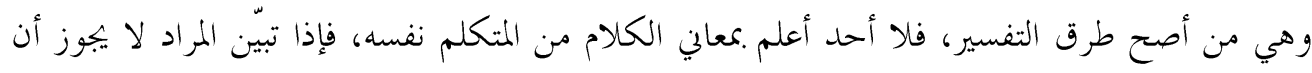

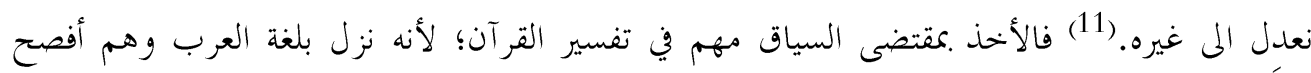

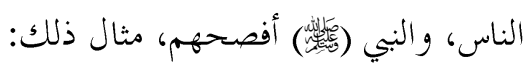

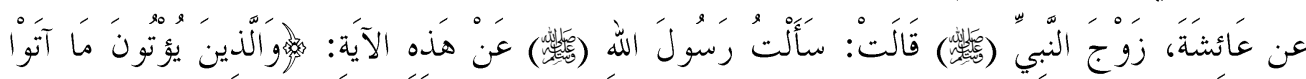

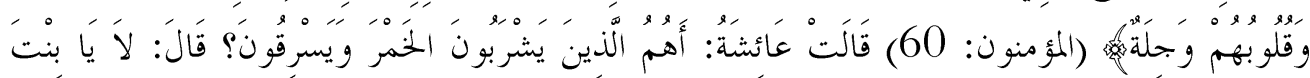

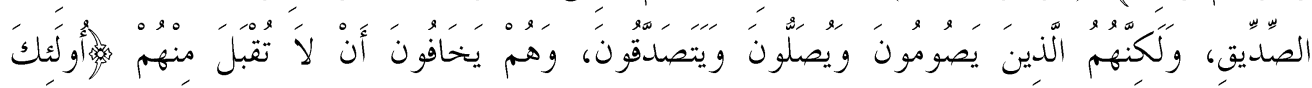

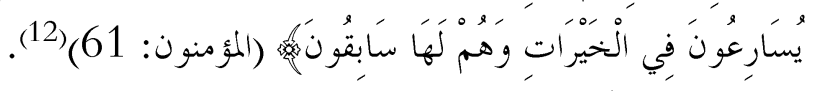

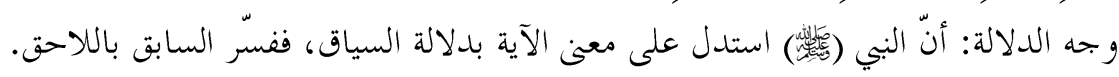

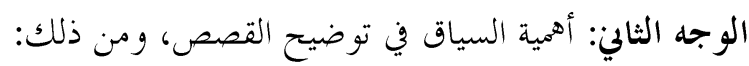

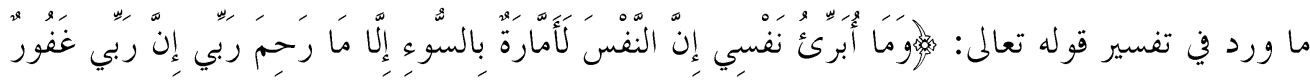

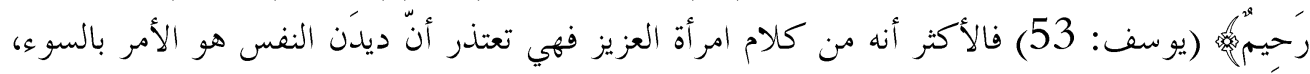

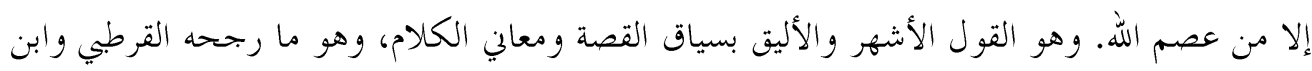

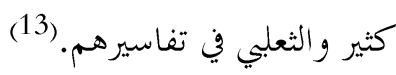

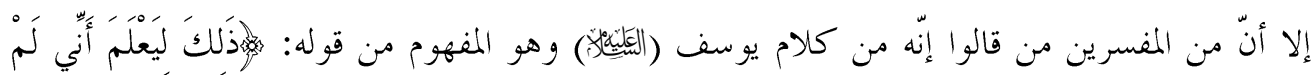

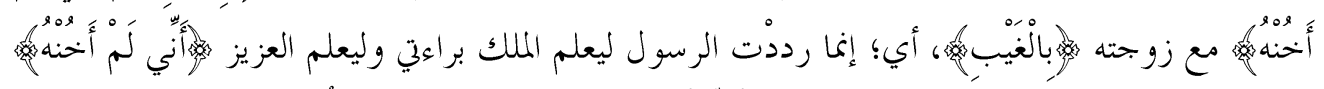

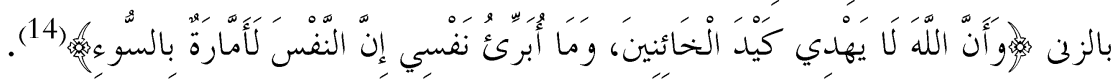




\section{الوجه الثالث: أهمية السياق في التشريع}

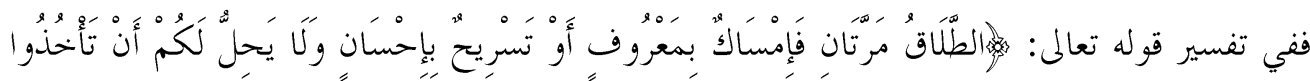

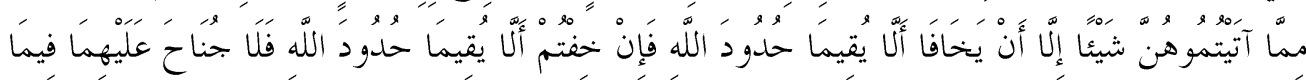

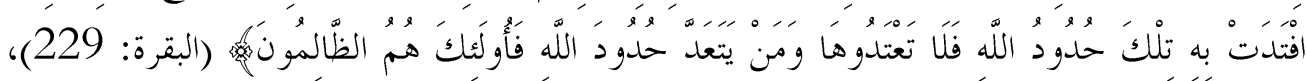

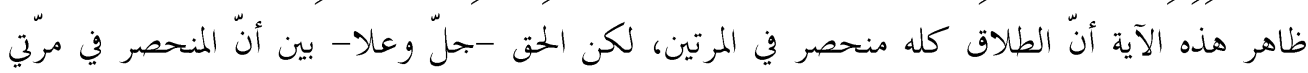

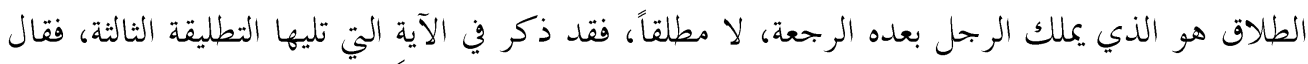

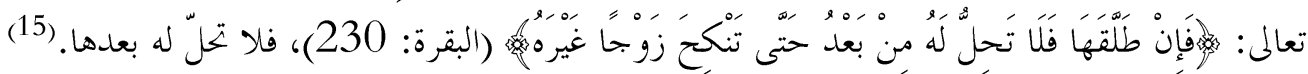

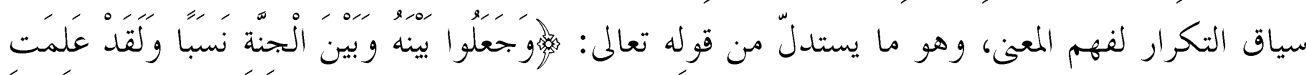

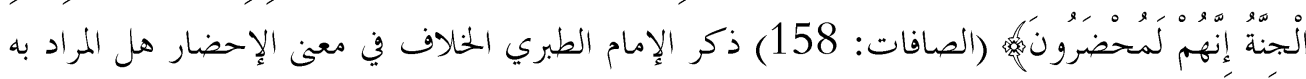

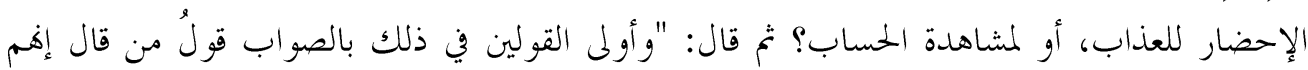

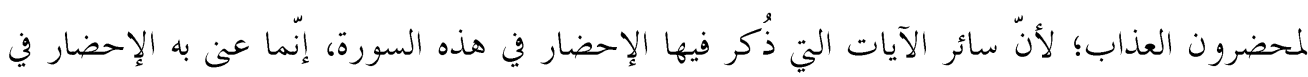
العذاب، فكذلك هذا الموضع"(16).

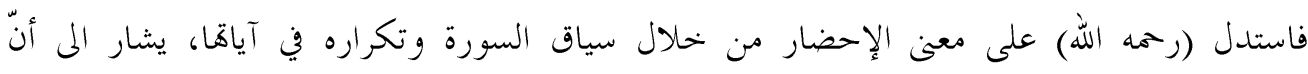

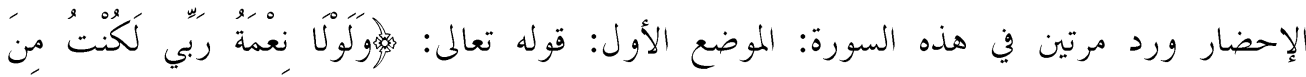

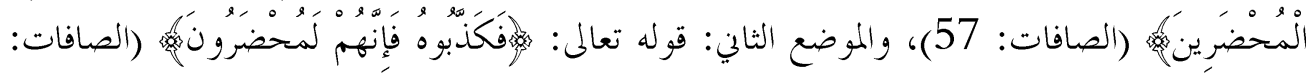

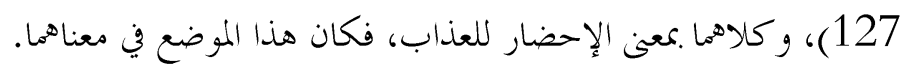

\section{المبحث الثابي: حكمية السياق والمعاني الكلية}

\section{المطلب الأول: حكمية السياق}

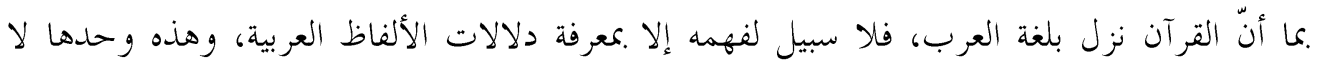

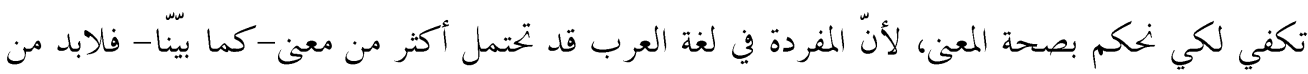

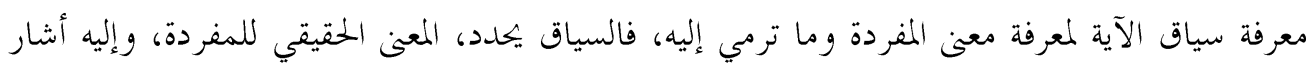
الشافعي (رحمه الله) بالقول: "فإنما خاطب الله بكتابه العرب بلساها على ما تعرف من من معانيها" (17).

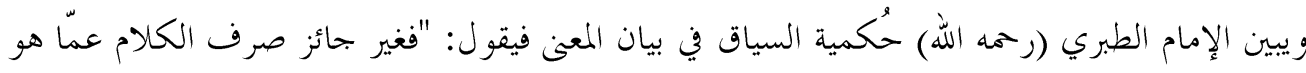

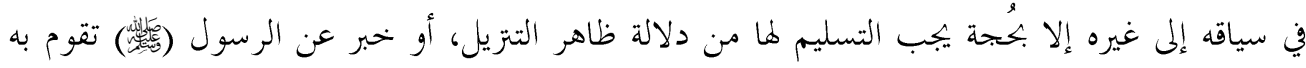
حجة، فأما الدعاوى فلا تتعذر على أحد" (18). 
وقال ابن تيمية (رحمه الله) مفصلاً في تقريره لهذه القاعدة، فبين أنّ أكثر ما وقع فيه الخطأ في التفسير من جهة الاستلال يرجع إلى سبين: "أحدها: قوم اعتقدوا معاني، ثم أرادوا حمل ألفاظ القر آن عليها. و الثاين: قوم فسروا القر آن مكجرد ما يسوغ أنْ يريده من كان من الناطقين بلغة العرب بكامه، من غير نظر إلى المتكلم بالقر آن، و المتزل عليه، و المخاطب به. فالأولون: راعَوا المعنى الذي رأوه من غير نظر إلى ما تستحقه ألفاظ القرآن من الدلالة والبيان. والآخَرون: راعَّا بحرّد اللفظ، وما يجيوز أن يريد به عندهم العربي من غير نظر إلى ما يصلح للمتكلم،

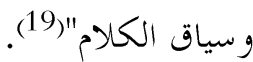
فيتبين من كلامه إرجاعه سبب الغلط إلى أمرين: الأول: إهمال دلالات الألفاظ العربية. و الثاني: إهمال دلالة السياق وقرائن الأحوال. ويؤ كد على أهمية دلالة السياق، وعلدم كفاية دلالة اللفظ فيقول: "فإنّ الدلالة في كل موضع بحسب سياقه، وما يجف به من القر ائن اللفظية و الحالية"(20). وقد عدّ هذا أصلاً عظيماً مهماً نافعاً في باب فهم الكتاب و السنة فقال: "بل ينظر في كل آية وحدىثث

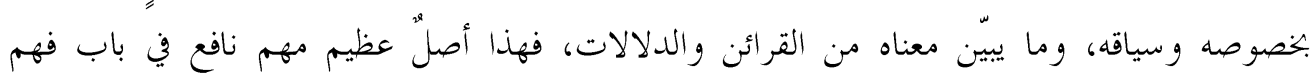

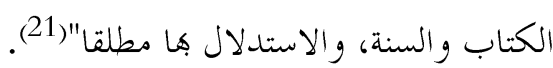
و من هنا يتضح لنا أنّ كلّ تفسير أُهملت فيه دلالاتُ الألفاظ، أو ئأباه السياق فهو باطل.

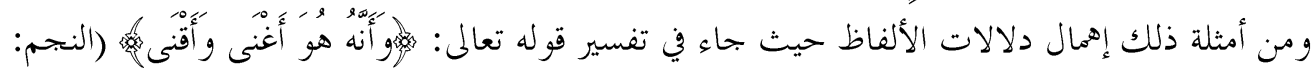

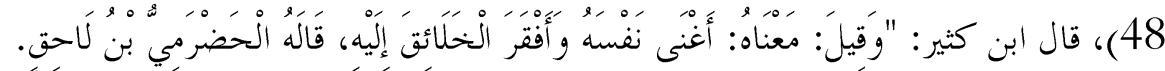

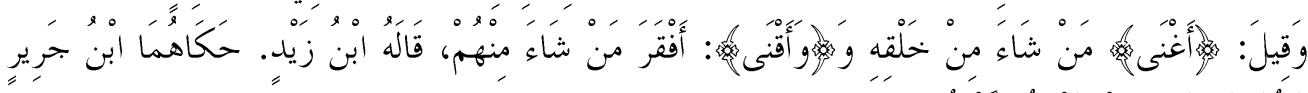

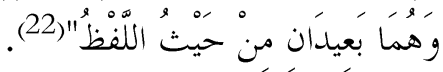

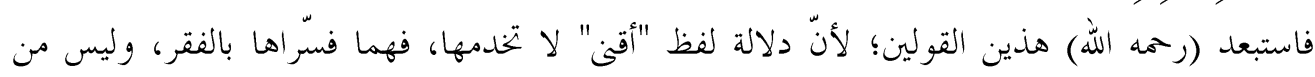
معانيها الفقر، بل قيل فيها قولان حكاهما الزجاج: أحدها: أقنى .كعين أرضى.

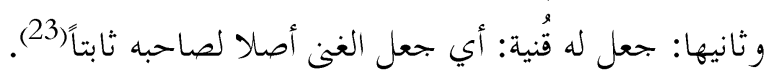
ومن هنا فهما بعيدان عن اللفظ. 
وفي قوله تعالى:

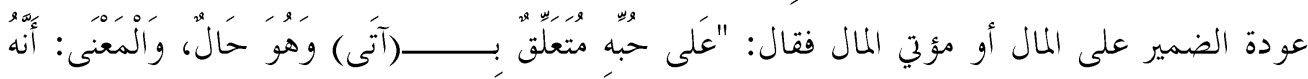

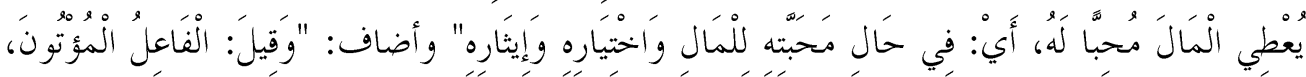

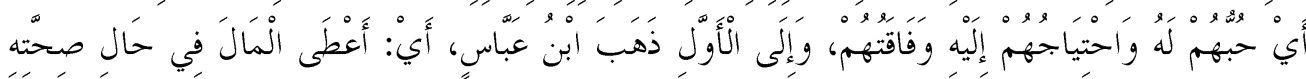

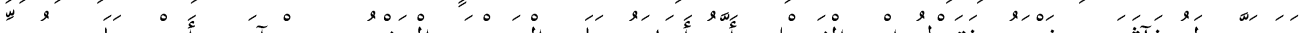

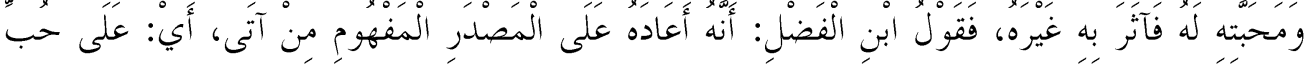

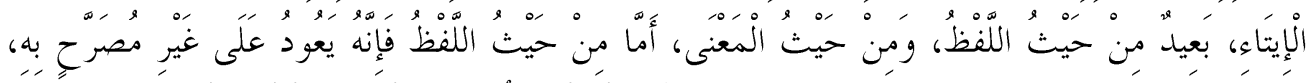

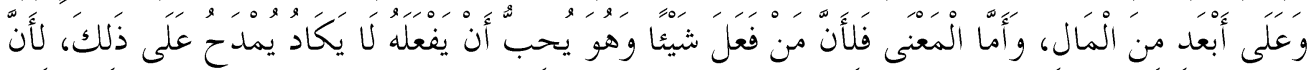

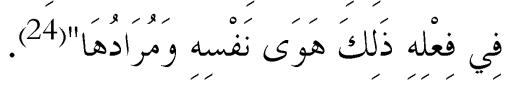

\section{المطلب الثالي: المعالي الكلية}

نعني بالمعاني الكلية: هو ما يرد في القرآن الكريم من ألفاظ يغلب استعماها على معنى واحد، وهو ما يسميه بعض العلماء به (كلىات الألفاظ).

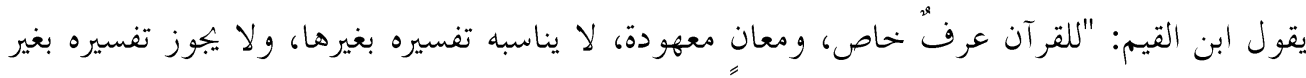

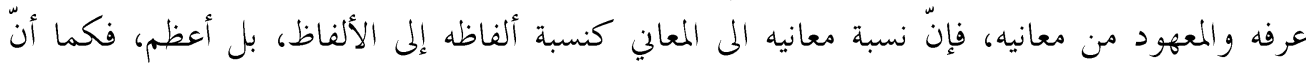

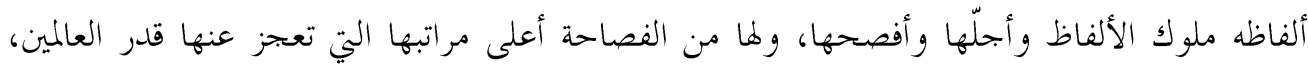

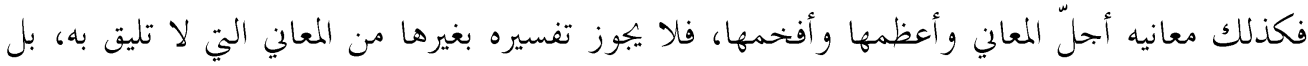

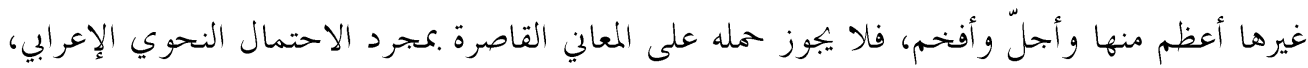
فتدبر هذه القاعدة، ولتكن منك على بال، فإنك تنتفع هـا في معرفة ضعف كثير من أقوال المفسرين

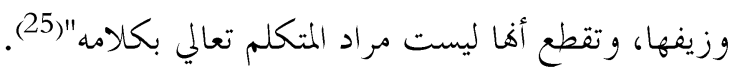

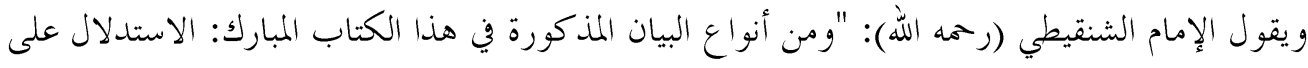

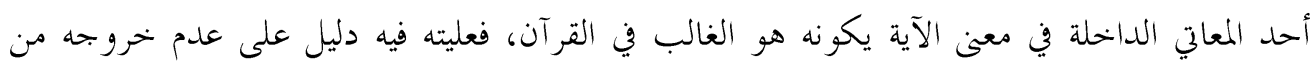
معنى الآية". ويقول الطاهر بن عاشور: "فلا جرم كان رائد المفسر -في ذلك- أي البيان أنْ يعرف على الإجمال مقاصد القرآن منا جاء لأجله، ويعرف اصطلاحه في إطلاق الألفاظ، وللتنزيل اصطلاح وعادات" (26).

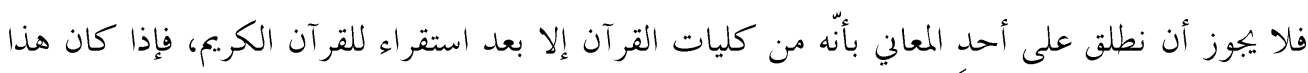

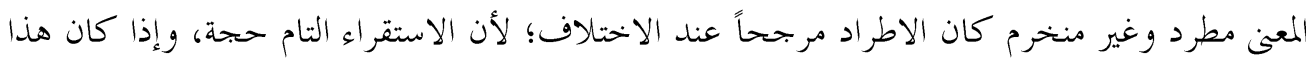


المعنى الكلي منخرم بأمثلة قليلة، فإنه حينئذ يبين المفسّر هذه الأمثلة، ويكون الحكم أغبي، ويمكن الاستفادة منه في الترجيح. (27)

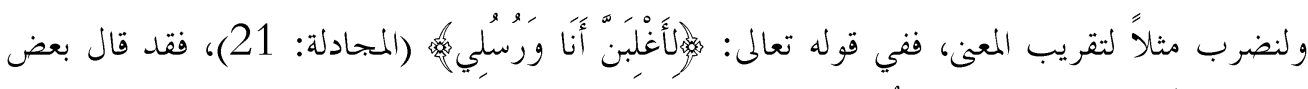

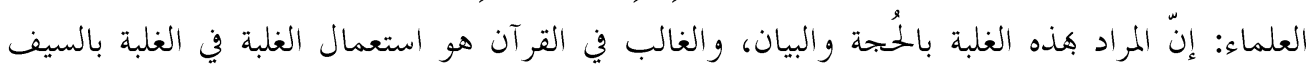

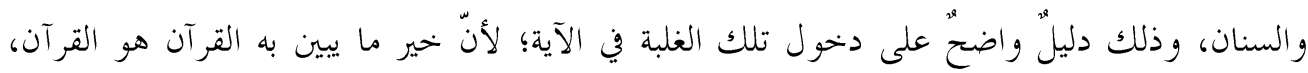

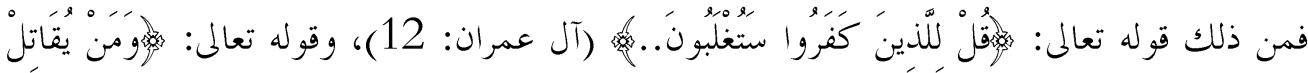

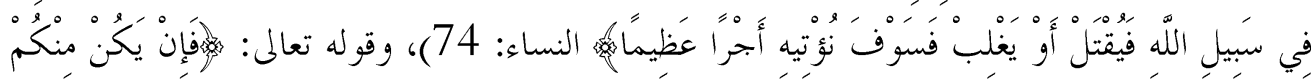

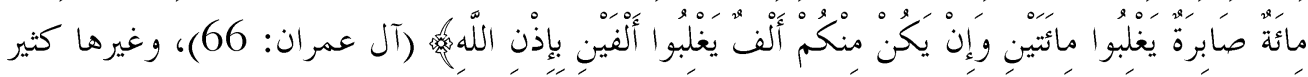

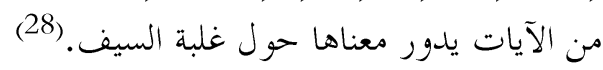
وعلى هذا المنو ال: (29)

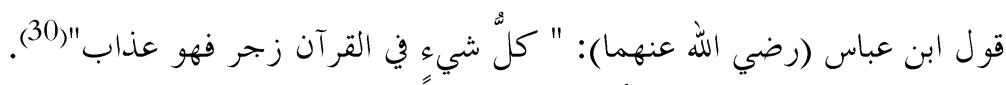

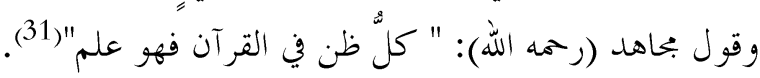

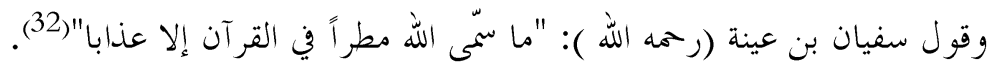

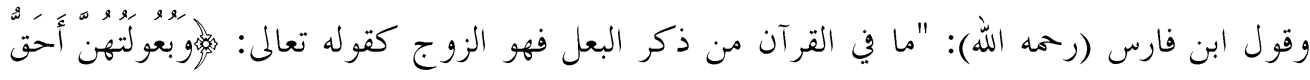

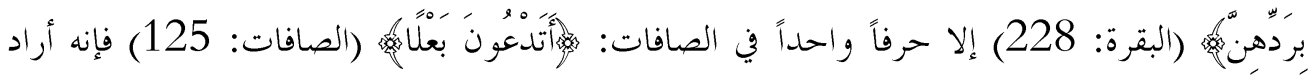

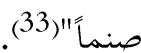

\section{المبحث الثالث: السياق يحدد معنى المفردة ذات المعاني الكثيرة}

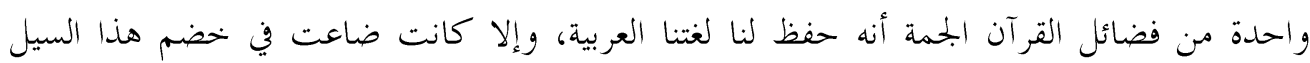

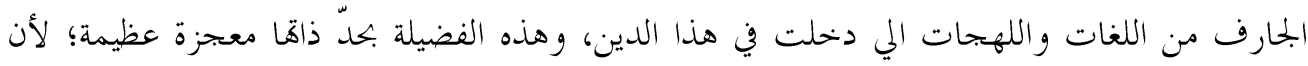
المفردة الواحدة ترد في القر آن الكريم مكعان كثيرة والذي يهدد معناها في كل مرة سياق الآية التي وردت

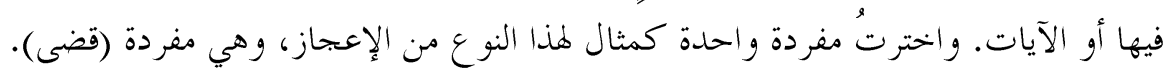

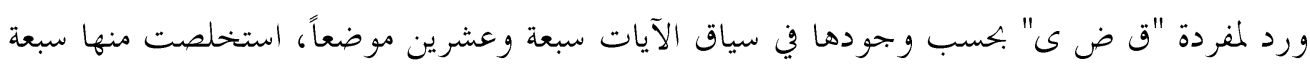

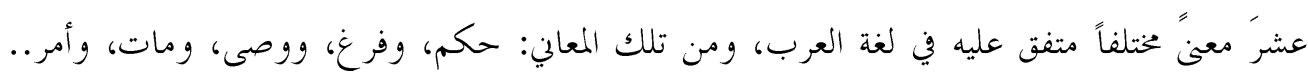

1- المعنى الأول و الثاني و الثالث: قضى .معنى "حكم" "صنع" "انتهى" 


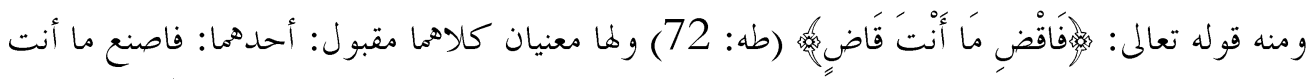

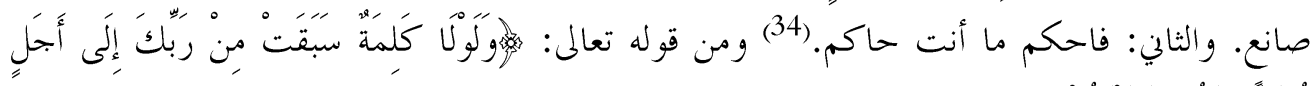

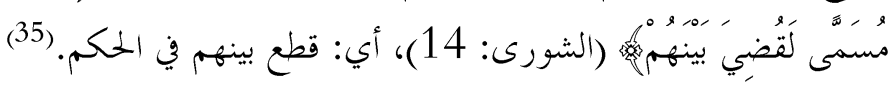

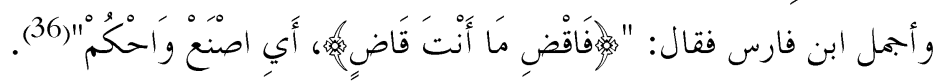

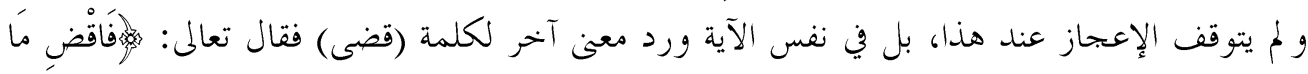

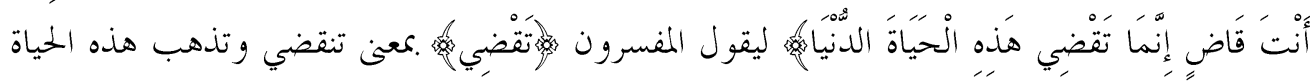

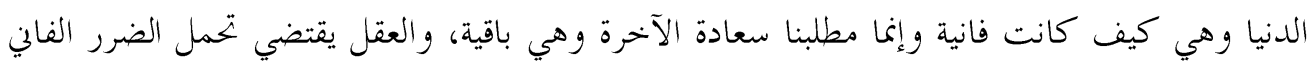
المتوصل به إلى السعادة الباقية.(37)

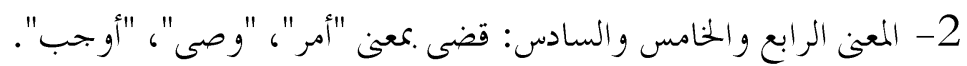

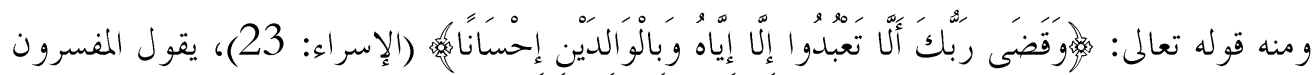

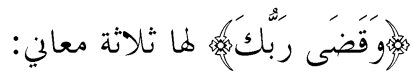

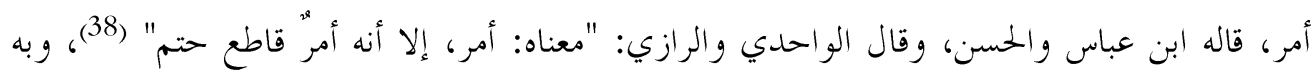

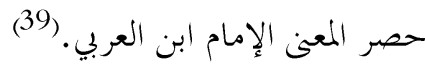

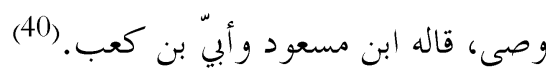
أوجب، قاله الربيع بن أنس.

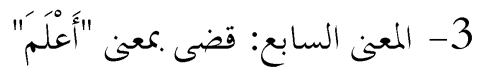

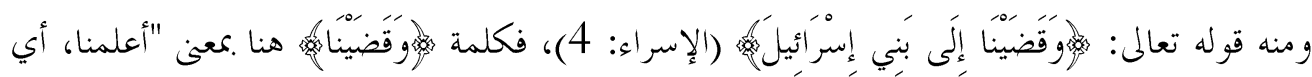
أعلمناهم إعلاماً قاطعاً. (42)

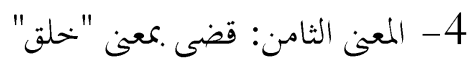

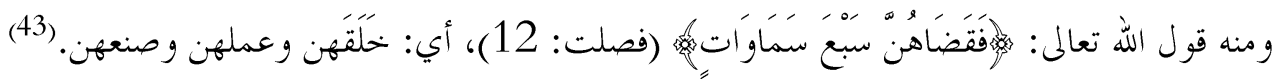
5- المعنى التاسع: قضى .كعنى "قدّر"

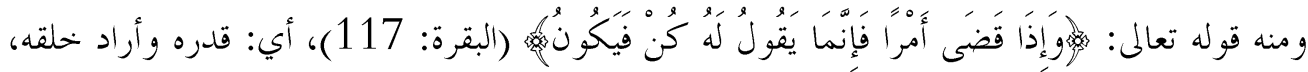

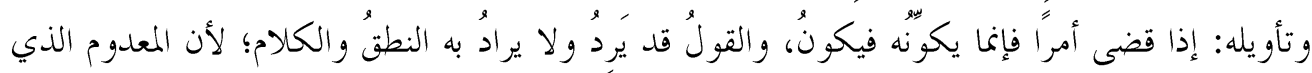

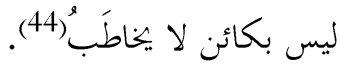

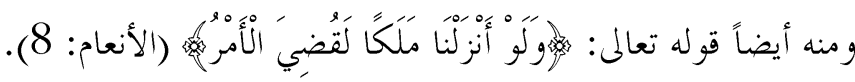

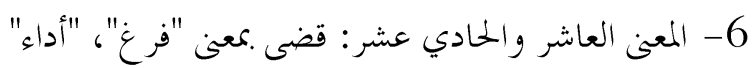




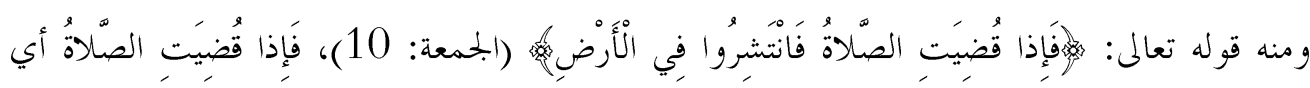
فرغ منها. وهو الأنسب لسياق السورة، وبه قال أكثر المفسرين. (45)

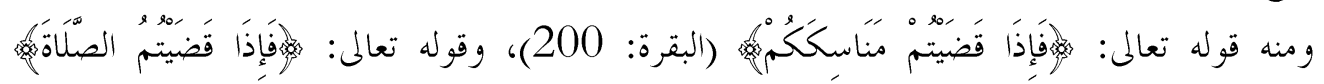
(النساء: (103)

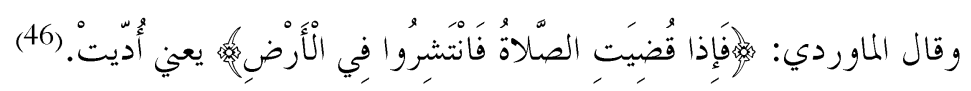
و يلاحظ هنا أنّ الأمر للندب؛ لأنه يقول: هذا الأمر ليس بفريضة، إنما هو أدب ورحمة من الله، فإن

$$
\begin{aligned}
& \text { كتب فحسن، وإن لم يكتب فلا بأس. (47) } \\
& \text { 7- المعنى الثاني عشر : قضى .كعنى "قتل }
\end{aligned}
$$

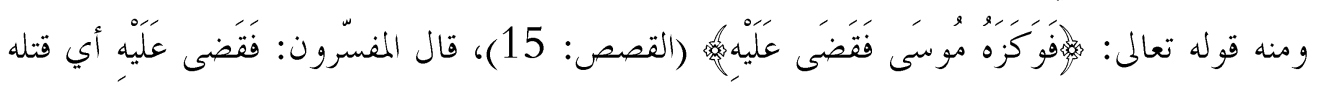

وفرغ من أمره، و كل شّ شيء فرغت منه فقد قضيته. (48)

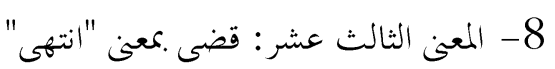

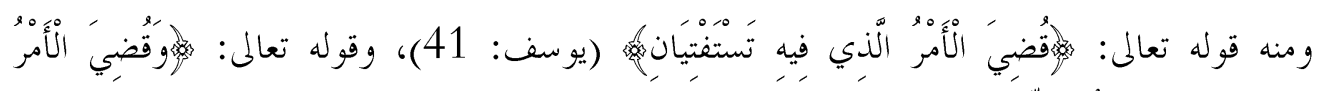

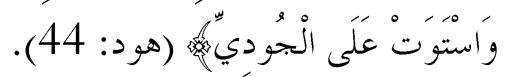

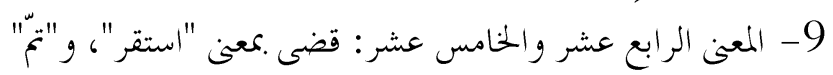

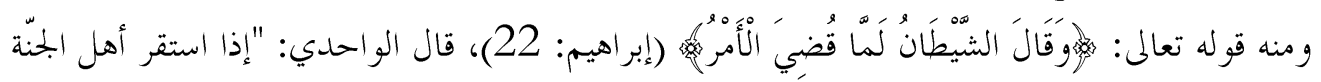
في الجنّة وأهل النار في النار، اجتمع أهل النار باللائمة على إبليس لعنه الله"(49).

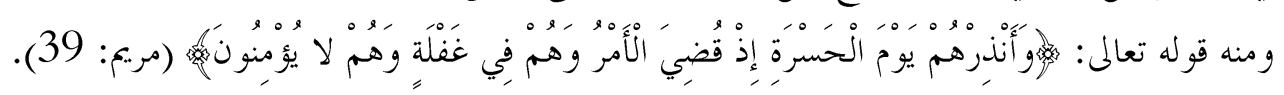

\section{الخاتمة:}

كان موضوع بحثنا حول التفسير بمقتضى السياق واهتمام المفسرين بتفسير المفردة بحسب موقعها من الآية وسياق الآيات، وقد تبين لي ما يأتي:

1- اختلف اللغويون في معنى السياق ولكن جميع معانيه تدور حول التتابع والتوالي والجمع. 2- و واختلف الاصطلاحيون في تعريف فاخترت التعريف الذي يقول: "تتابع المفردات والجمل والتراكيب القرآنية المترابطة لأداء المعنى.

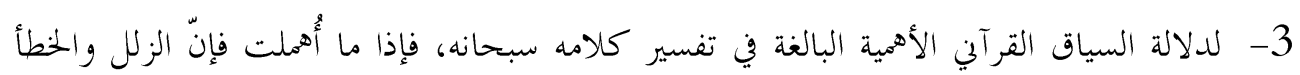

$$
\text { واقع لا لا عحالة. }
$$

4- كلّ تفسير أُهملت فيه دلالات الألفاظ، أو يأباه السياق فهو باطل. 
5- المعاني الكلية: هو ما يرد في القرآن الكريم من ألفاظ يغلب استعمالها على معنى واحد، وهو ما

يسميه بعض العلماء به.

6- ضربنا مثلاً لأهمية السياق في تفسير المعنى لمفردة (ق ض ى) حيت الختلفت معانيها في الآيات القر آنية واستحضرنا منها خمسة عشر معنى.

1.

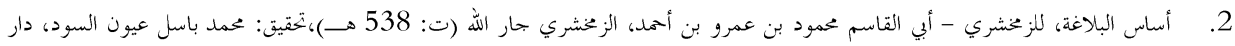

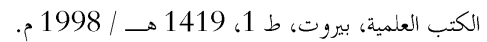

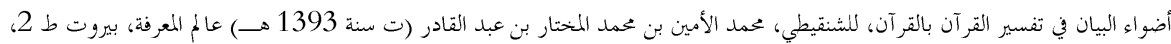

1403 هـ 1983 م. 1983

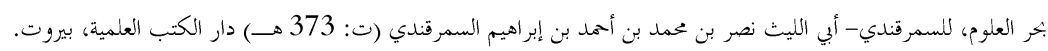

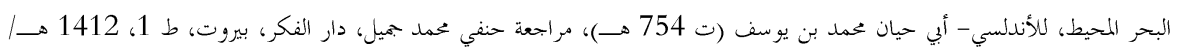

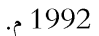

البرهان في علوم القرآن، للزر كشي-بدر الدين محمد بن عبد اللّا الزركشي، تمقيق محمد أبو الفضل إبراهيم، دار أحياء الكتب العربية عيسى البابى

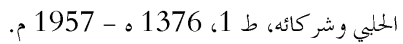

• تاج العروس من جواهر القاموس، للزبيدي- أبي الفيض محمّل بن محمّل بن عبد الرزّاق الحسيين (ت: 1205 هـ/1790 م) دار الهداية،

دمشق.

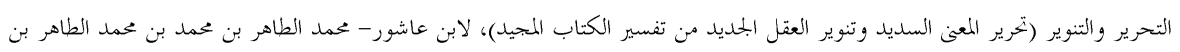

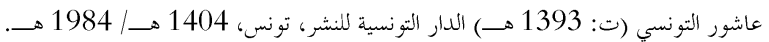

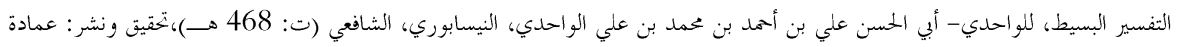

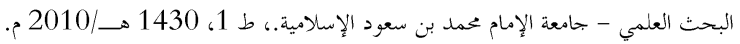

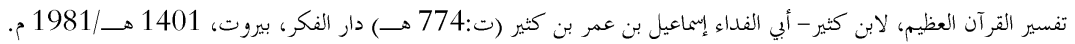

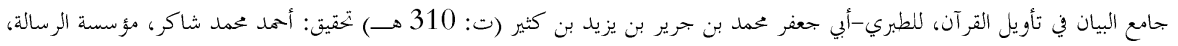
.11

12. الجامع الصحيح، للترمذي- أبي عيسى محمد بن عيسى (ت:279 هــ)، تحقيق: بشار عواد معروف، دار إحياء الغرب الإسلامي، بيروت، ط

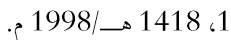

البحامع لأحكام القر آن، القرطبي -أبو عبداللة محمد بن أحمد بن أبي بكر (ت:671 هــ)، تحقيق أحمد عبد الحليم البردوبي، دار الشعب، القاهرة،

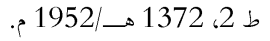

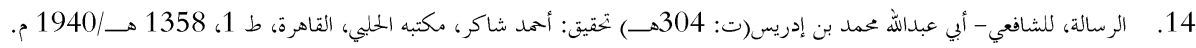

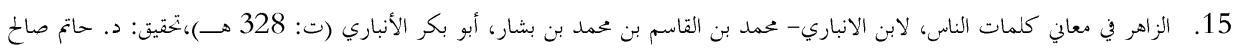

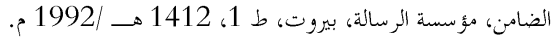

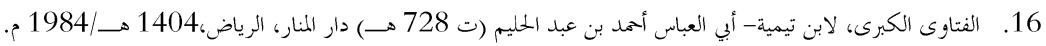

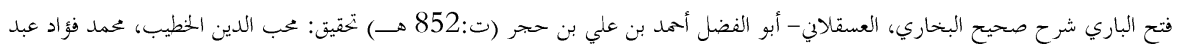

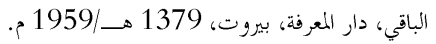

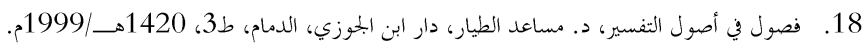

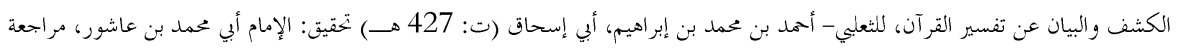

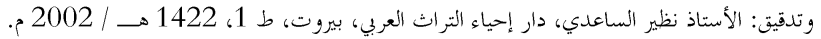

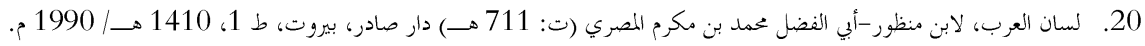


21. المخصص، لابن سيده- المؤلف: أبو الحسن علي بن إسماعيل بن سيده المرسي (المتوف: 458 هـ) تخقيق: خليل إبراهم جفال، دار إحياء التراث

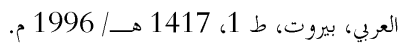

22. مفاتيح الغيب المسمى التفسير الكبير، للرازي - فخر الدين بن ضياء الدين عمر إمام الري (ت:604 هـــ قدم له الشيخ خليل الميس، دار

$$
\text { الفكر، بيروت، } 1415 \text { هـ/ 1995 م. }
$$

23. مقدمة في أصول التفسير، لابن تيمية- أبي العباس أمهد بن عبد الحليه(ت: 728هـ)، تحقيق: عدنان زرزور، دار القرآن الكربع، بيروت، ط3،

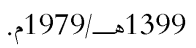

24. معالم التنزيل، للبغوي -أبي حمدد الحسين بن مسعود الفراء (ت 516 هـ) تحقيق: خالد العلك، مروان سوار، دار المعرفة /بيروت، ط 21407

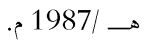

25. معاني القران وإعرابه، للزجاج- أبي إسحق إبراهيم بن السري (ت:311 هـ) تحقيق: عبد الجليل عبده شبي، دار الحديث، القاهرة، ط2،

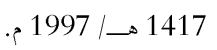

26. المعجم الكبير، للطبراني- سليمان بن أحمد بن أيوب بن مطير اللخمي الشامي، أبو القاسم الطبراني (ت: 360هـ)، تحقيق: حمدي بن عبد

$$
\text { المجيد السفي، مكتبة ابن تيمية ، القاهرة. }
$$

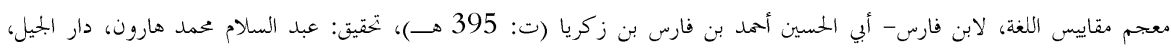

$$
\text { بيروت،1399 هـ/ } 1979 \text { م. }
$$

المعتم الوسيط لمجموعة من العلماء (إبراهيم مصطفى ـ أحمد الزيات ـ حامد عبد القادر ـ عمدد النجار)، دار الفكر، بيروت 1401 هـ

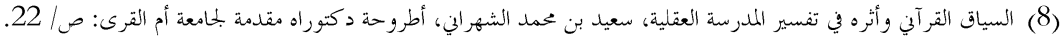

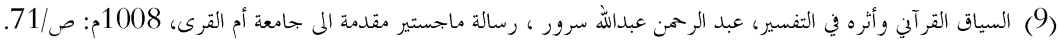

280/2 (10) المخصص، لابن سيده

(11) مقدمة في أصول التفسير، لابن تيمية، ص/93. والفتاوى الكبرى، لابن تيمية، 363/13.

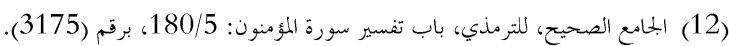

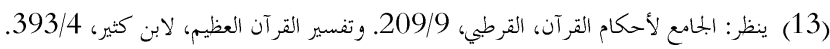




$$
\begin{aligned}
& \text { (14) ينظر: جامع البيان في تأويل القرآن، للطبري، 142/16. وبحر العلوم، للسمرقندي، 197/2. }
\end{aligned}
$$

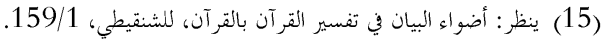

$$
\begin{aligned}
& \text { (16) (15) بامع البيان: 646/19. }
\end{aligned}
$$

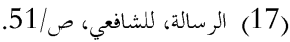

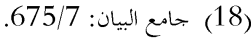

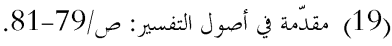

$$
\begin{aligned}
& \text { (20) بحموع الفتاوى: 14/6. } \\
& \text { (21) (21) المصدر نفسه: 18/6. }
\end{aligned}
$$

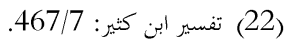

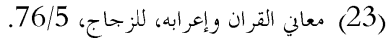

$$
\begin{aligned}
& \text { (24) البحر المحيط، للأندلسي، 135/2. }
\end{aligned}
$$

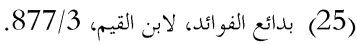

(26) مقدمة التحرير والتنوير (تحرير المعنى السديد وتنوير العقل الجديد من تفسير الكتاب المجيد)، لابن عاشور، 39/1.

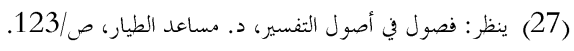

18/1: 28)

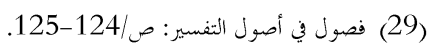

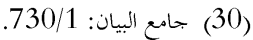$$
625 \text { / } 621 \text { (31) المصدر نفع اليان: }
$$

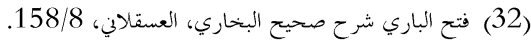

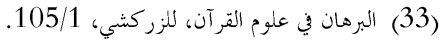

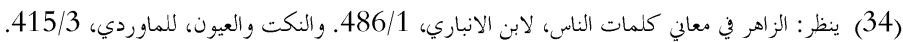

$$
\text { (35) التفسير البسيط، للواحدي، 268/3. }
$$

(36) معجم مقاييس اللغة، لابن فارس، $35 / 5$ (35/5)

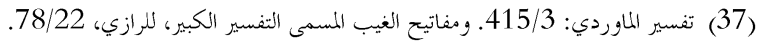

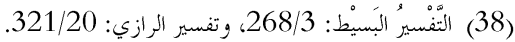

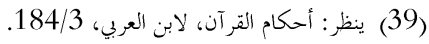

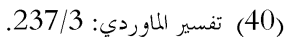
126/3. 268/3.

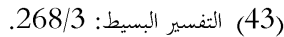
268/3. (45) ينظر: التفسير البسيط: 232/7. وتفسير البغوي: 93/5، والكشف والبيان عن تفسير القرآن، للثعبي، 316/9، 316/3. (46) تفسير الماوردي: 10/6، وهو قول ابن عباس. ينظر: التفسير البسيط: 458/21. (47) التفسير البسيط: 485/4.

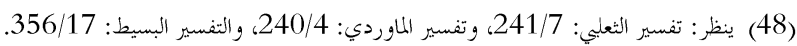
(49) التفسير البسيط: 449/12، وتفسير الرازي: 84/19. 